\title{
Una monodosis de dexamentasona oral demostró ser útil en el crup leve
}

\section{Objetivo}

Determinar el beneficio de una monodosis de dexamentasona oral para el alivio de los síntomas producidos por laringotraqueobronquitis (crup) leve.

\section{Diseño}

Ensayo clínico aleatorizado, controlado y doble ciego, con análisis por intención de tratar.

\section{Lugar}

Estudio multicéntrico (4 guardias pediátricas) de Canadá.

\section{Pacientes}

Ingresaron al estudio $720(24,8 \%)$ pacientes que cumplían los criterios de crup leve de un total de 2901 evaluados. Se consideró crup leve si la tos perruna se había iniciado dentro de las 72 horas y al examen físico presentaba un puntaje de hasta 2 en la escala de Westley (ver abajo)

\section{Intervención}

Los pacientes fueron aleatorizados a recibir una única dosis oral de dexametasona de $0,6 \mathrm{mg} / \mathrm{kg}$. -hasta un máximo de $20 \mathrm{mg}$ - $(\mathrm{n}=359)$ o placebo $(n=361)$.

\section{Medición de resultados principales}

Se consideró como resultado principal la reconsulta por tos perruna dentro de los 7 días de la intervención. Resultados secundarios fueron la persistencia sintomática en los 3 días posteriores a la intervención; el costo para los padres y para el estado canadiense;

el estrés de los padres; y las horas de sueño perdidas por los niños.

\section{Resultados}

En el grupo placebo 54 niños (15.3\%) reconsultaron dentro de los 7 días, comparado con 26 (7.3\%) del grupo intervención (ver tabla). El análisis económico determinó que cada caso del grupo placebo le costó al estado un promedio de 93 dólares canadienses contra los 72 del grupo dexametasona (ahorro promedio de 21 dólares canadienses). Las horas perdidas de sueño en el grupo placebo fueron en promedio 4,2 contra 2,9 del grupo intervención $(p<0.001)$. La disminución del estrés paterno durante el primer día fue pequeña, pero a favor del grupo dexamentasona, no se encontró diferencia en los días sucesivos. No hubo sangrados gastrointestinales ni diferencias entre los grupos en las reacciones adversas.

\section{Tabla de resultados principales}

\begin{tabular}{l|c|c|c|c|c|}
\multicolumn{1}{|c|}{ Resultados } & $\begin{array}{c}\text { Placebo } \\
\text { (n: 361) }\end{array}$ & $\begin{array}{c}\text { Dexametasona } \\
\text { (n: 359) }\end{array}$ & $\begin{array}{c}\text { Odds Ratio } \\
\text { (IC95\%) }\end{array}$ & $\begin{array}{c}\text { RRA } \\
\text { (IG95\%) }\end{array}$ & $\begin{array}{c}\text { NST } \\
\text { (IC95\%) }\end{array}$ \\
\hline $\begin{array}{l}\text { Reconsulta dentro de } \\
\text { los 7 días }\end{array}$ & $15,3 \%$ & $7,3 \%$ & $2,4(1,4-3,9)$ & $8 \%(3,3-12,5)$ & $13(8$ a 31$)$ \\
\hline
\end{tabular}

RRA: reducción de riesgo absoluto; NNT: número necesario a tratar

\section{Conclusiones}

Una monodosis de $0,6 \mathrm{mg} . / \mathrm{kg}$. de dexametasona oral demostró pequeños pero importantes beneficios en el tratamiento de niños con crup leve.

Fuente de Financiamiento: Fundacions canadienses sin fines de lucro. Uno de los autores declaró haber recibido apoyo económico por parte de Cumberland Pharmaceuticals.

Escala de Severidad del Crup de Westley (puntaje máximo de 17)

Grado de estridor (en reposo, sin llanto): $\quad$ Grado de retracción costal/subcostal: 0 : sin estridor

: estridor audible con el estetoscopio.

2: estridor audible sin el estetoscopio. 2 2: retracción moderada.

2: retracción moderada.

\section{Comentario}

La "laringitis" es una entidad extremadamente frecuente en la atención primaria pediátrica, especialmente los casos más leves, aquellos que se presentan en pacientes en buen estado general únicamente con la típica tos perruna o de "foca", sin estridor ni tiraje ${ }^{1,2}$. Desde hace algunos años, y extrapolando los beneficios demostrados por los corticoides en el crup moderado y severo, se ha difundido la práctica empírica de tratar la tos perruna con corticoides $^{3.5}$. Este trabajo pionero por su rigurosidad y cantidad de pacientes, al decir de sus autores ha demostrado "pequeños pero importantes beneficios" de una monodosis de dexamentasona para el alivio de los síntomas producidos por el crup leve.

¿Esto quiere decir que a partir de Septiembre del 2004 la evidencia nos avala para tratar a todos nuestros pacientitos con crup leve con corticoides?

Hay algunos puntos que relativizan esta afirmación: 1) El principal es la naturaleza autolimitada del crup leve. El tratamiento con corticoides es una medida sintomática; no se indica con la idea de evitar la progresión hacia un estadío más severo; 2) El beneficio del tratamiento expresado en NNT determina que hay que tratar a 13 niños para evitar que uno reconsulte dentro de los 7 días; 3) Si bien hay estudios en niños asmáticos acerca de la seguridad de cursos cortos de corticoides, no se han realizado estudios a largo plazo en niños con crup; 4) La dosis de $0,6 \mathrm{mg} / \mathrm{kg}$. es la dosis "estándar" canadiense y la que se suele usar de forma parenteral en situaciones de guardia en los crups moderados y severos. En la
Argentina, los corticoides para el crup leve suelen ser indicados en 2 o 3 tomas diarias durante 3 a 5 días y en dosis mucho menores a $0,6 \mathrm{mg} / \mathrm{kg} / \mathrm{dí}$ de dexametasona.

No existen preparados en gotas ni en jarabes de dexametasona en nuestro medio. La dosis utilizada en este trabajo $(0.6 \mathrm{mg} / \mathrm{kg}$., hasta un máximo de $20 \mathrm{mg}$.) equivale a $3,2 \mathrm{mg} / \mathrm{kg}$ de meprednisona o metilprednisolona, $0.6 \mathrm{mg} / \mathrm{kg}$ de betametasona, $04 \mathrm{mg}$ de prednisona o prednisolona. Esta dosis implica que un niño de 3 años con un peso de $15 \mathrm{~kg}$. debe ingerir $15 \mathrm{ml}$ meprednisona o entre 15 y $18 \mathrm{ml}$ de betametasona (según el preparado comercial). Siendo que estos fármacos se presentan en envases de 15 a $30 \mathrm{ml}$. para ser usados en gotas, puede resultar inaceptable para algunos padres y profesionales que el niño reciba el frasco entero.

\section{Conclusiones del Comentador}

Este estudio avala una práctica empírica habitual, con una dosis no convencional en nuestro medio, que debería reservarse para casos muy sintomáticos o frente padres agotados o demandantes. Es probable que este estudio motive la realización de otros similares que sometan a prueba dosis menores de corticoides, ya que estudios pequeños han demostrado el beneficio de monodosis de 0.15 y $0,3 \mathrm{mg}$. de dexametasona.

\section{Dr. Sebastián Fernández [ Responsable CAP San Martín.Balcarce, Pcia. de Bs. As. ]}

Fernandez S. Una monodosis de dexamentasona oral demostró ser útil en el crup leve. Evid. actual. práct. ambul. 2005;8:8. Comentado de: A randomized trial of a single dose of oral dexamethasone for mild croup. Bjornson CL, Klassen TP, Williamson J, et al. for the Pediatric Emergency Research Canada Network. N Engl J Med 2004;351:1306-13. PMID: 15385657

\section{Referencias}

1. Dominic A Fitzgerald and Henry A Kilham. Croup: assessment and evidence-based management. Medical Journal of Australia. 2003; 179 (7): $372-377$.

2. ML Arroba Lasanta. Laringitis aguda (Crup). Anales de Pediatría 2003; Monog.1(1): 55 - 61

3. Klass P. Croup--the bark is worse than the bite. Comment on: N Engl J Med. 2004 Sep 23;351(13):1306-13

4.Vernacchio L, Mitchell AA. Oral dexamethasone for mild croup. N Engl J Med. 2004 Dec 23:351(26):2768-9; author reply 2768-9.

5. Ebell M. Single oral dose dexamethasone effective for even mild croup. Acceso online el 20 de Febrero de 2005 en :http://www.infopoems.com/infopoems/showPOEM.cfm?ID=61101 